\title{
Viral, bacterial or both? Regardless, we need to treat infection in COPD
}

\author{
Tobias Welte ${ }^{1,2}$ and Marc Miravitlles ${ }^{3}$
}

\begin{abstract}
Affiliations: 'Dept of Respiratory Medicine, Medizinische Hochschule Hannover, Germany. ${ }^{2}$ German Centre of Lung Research, Hannover, Germany. ${ }^{3}$ Pneumology Dept, Hospital Universitari Vall d'Hebron, Ciber de Enfermedades Respiratorias (CIBERES), Barcelona, Spain.
\end{abstract}

Correspondence: Marc Miravitlles, Pneumology Dept, Hospital Universitary Vall d'Hebron, P. Vall d'Hebron 119-129, 08035 Barcelona, Spain. E-mail: mmiravitllesđavhebron.net

$\mathbf{0}$ @ERSpublications

Specific prevention of infective exacerbations of COPD is required http://ow.ly/vdIIh

Guidelines indicate that pharmacological treatment of chronic obstructive pulmonary disease (COPD) is based on bronchodilators with the addition of inhaled corticosteroids (ICS) in frequent exacerbators [1]. Although this recommendation is in accordance with the best evidence available, it does not take into account that more than half of the exacerbations are infective and infections are not adequately prevented or treated by ICS. In fact, no pharmacological treatment has been able to suppress all exacerbations and, on the contrary, the long-term use of ICS has been associated with higher airway bacterial load in stable COPD [2], and increased risk of pneumonia [3] and tuberculosis [4].

Clinicians have always been aware that not all exacerbations of COPD are alike. Some must be treated with anti-infective agents while others respond better to systemic corticosteroids. Markers such as sputum colour and C-reactive protein levels are useful to differentiate exacerbations and guide therapy [5, 6]. Recent studies have further characterised these different types of exacerbations, and identified bacterial, viral, inflammatory (eosinophilic) and pauci-inflammatory phenotypes of exacerbations, with the majority (59\%) of exacerbations being bacterial or viral. Interestingly, the phenotype of the exacerbation remains constant in a given patient [7]. However, despite these different phenotypes of exacerbations, no studies have attempted to investigate whether different treatments would be more effective in preventing one type of exacerbation or another.

Both the high bacterial load in the airways in stable COPD and an increased frequency of exacerbations have been associated with a more rapid decline in lung function and an impairment in quality of life [8-10]. More recently, the presence of bronchiectasis in patients with COPD [11] and the persistent colonisation by unusual microorganisms [12] have also been associated with increased mortality. These findings justify the identification of an "infective phenotype" that is usually a frequent exacerbator with mucous hypersecretion producing dark sputum during the stable state that is more abundant during exacerbations, and who requires frequent courses of antibiotics and probably demonstrates cylindrical bronchiectasis on computed tomography [13]. Treatment with bronchodilators and ICS never fully prevents infective exacerbations in this phenotype of patients.

In order to treat patients with frequent infective exacerbations better, we need to understand the pathogenesis of acute and chronic bronchial infection in COPD. GEORGE et al. [14] studied sputum samples from 77 patients with COPD during the stable state and exacerbations, and used real-time quantitative PCR for both human rhinovirus (HRV) and usual respiratory bacteria. They found that HRV prevalence and load during exacerbation were significantly higher than in the stable state and no HRV was found 1 month after the exacerbation. This observation confirms previous results obtained by other investigators. The

Received: March 032014 | Accepted: March 042014

Conflict of interest: Disclosures can be found alongside the online version of this article at www.erj.ersjournals.com

Copyright (CERS 2014 
increase in the prevalence and load of microorganisms during exacerbations has also been observed in the seminal studies by Monsó et al. [15] and Hill et al. [16], and has more recently been confirmed by GARCHA et al. [2] using microbiological culture and the more sensitive quantitative PCR as in the current study by GeOrge et al. [14]. Among others, these studies support the "fall and rise" hypothesis that suggests that exacerbations originate from an uncontrolled increase in bacterial and/or viral load in the airways that is paralleled by an increase in local (bronchial) and systemic inflammation [17]. In this context, there is growing evidence that the interaction between viruses and bacteria is crucial for the development of infective exacerbations, and in a significant number of cases, the viral infection can be the precipitating factor for a subsequent bacterial episode.

Viruses account for $\sim 30 \%$ of exacerbations, either alone or as copathogens, with the most frequent being picornaviruses (especially rhinovirus), influenza virus and respiratory syncytial virus [18]. Viral exacerbations have been associated with more severe respiratory symptoms, a higher rate of additional symptoms (cold, sore throat, increased dyspnoea and fever), slower recovery and frequent previous exacerbations [19]. Co-infection with viruses and bacteria can be found in 20-30\% of hospitalised COPD exacerbations, being particularly important in severe cases [20].

Viral infection may facilitate subsequent bacterial infection or increase the number of bacteria already present in the lower airways [21]. The relationship between upper-respiratory viral infection and COPD exacerbations has been demonstrated by MALLIA et al. [22] in a study with experimental rhinovirus infection in COPD patients and healthy subjects. After being infected with rhinovirus, COPD patients developed more severe and prolonged respiratory symptoms, greater lung function impairment and increased airway inflammation, all resembling naturally occurring exacerbations [22]. Moreover, rhinovirus infection induces impairment of antibacterial host defence [23] and alters the respiratory microbiome [24], with a subsequent rise in bacterial burden and an outgrowth from bacteria present at baseline that precipitates bacterial infection. This human experimental model has been confirmed by the clinical results presented by GEORGE et al. [14] in their cohort of patients in which the exacerbations that were positive for HRV but negative for bacteria at presentation presented a significant increase in bacterial load, with $73 \%$ becoming positive for bacteria by day 14 . In a significant number of patients this peak in bacterial load was associated with an increase in respiratory symptoms.

The findings described above challenge the concept of the acquisition of a new bacterial strain as the main cause of a bacterial exacerbation. This concept was developed by SETHI et al. [25], who observed that isolation of a new strain of a common respiratory bacterium in sputum was associated with a significantly increased risk of an exacerbation (relative risk 2.15, 95\% CI 1.83-2.53). However, during the study, there was a large number of medical visits with isolation of a new strain without associated exacerbation, and in $15.4 \%$ of visits in which no new strain was identified, the patients had clinical symptoms of an exacerbation. Their results indicate that acquisition of new strains of bacteria may also be an initiating event for an exacerbation, but not the only one. A complex host-pathogen interaction in the airways probably determines the outcome of each new bacterial strain acquisition in COPD, and the balance between host defense and pathogen virulence determines the level of proliferation of the pathogen, which, in turn, determines the increase in airway inflammation. Large increases in airway inflammation result in greater physiological changes, which lead to enough symptoms to be identified as an exacerbation. When the adaptive immune response limits the proliferation of the pathogens or dampens the inflammation, the bacterial infection is addressed as colonisation [26]. Are these two mechanisms, change in bacterial strain and previous viral infection, independent of each other? It is difficult to say, because no viral detection was performed in the studies by SETHI et al. [25] and no strain identification was made in most studies analysing the virus-bacterium interaction. We have enough evidence to suggest that a change in bacterial strain is associated with the initiation of an exacerbation, and that viral infection is associated with exacerbation and subsequent bacterial infection. It is possible that viral infection can lead to an infection by a new bacterial strain and both mechanisms could coexist in a given patient, but apparently both can initiate an exacerbation by themselves.

The interaction between viral and bacterial infection has a practical implication for management. Episodes of exacerbation that initiate with cold symptoms, indicative of a viral infection [19], might be treated with antibiotics due to the high prevalence of subsequent bacterial infection, at least in severe COPD patients at high risk of poor outcomes [27], particularly if treatment with antibiotics is delayed [28]. In fact, there is a strong relationship between colds and exacerbations, both of which peak during the winter. More than $40 \%$ of colds fulfil the definition of an exacerbation of COPD and in exacerbations associated with a cold, coryzal symptoms occurred prior to the onset of exacerbations in $84 \%$ of cases [29].

In summary, both viruses and bacteria are part of the natural history of COPD. They interact in different ways and result in episodes of increased loads and associated inflammation that are identified as 
exacerbations, or may persist at low loads with inflammation of low intensity, which is commonly known as colonisation, but more appropriately called chronic bronchial infection. Both acute and chronic infection have a role in disease progression and are usually not considered in treatment guidelines that focus the pharmacological management of COPD with bronchodilators and ICS. It is questionable whether COPD patients with chronic infection should be treated similarly to those without; they probably require an individualised approach [30]. The interaction between infection-related and COPD-specific pathophysiology should be taken into account in further studies on either the prevention or therapy of COPD exacerbations.

\section{References}

1 Celli BR, MacNee W, ATS/ERS Task Force. Standards for the diagnosis and treatment of patients with COPD: a summary of the ATS/ERS position paper. Eur Respir J 2004; 23: 932-946.

2 Garcha DS, Thurston SJ, Patel AR, et al. Changes in prevalence and load of airway bacteria using quantitative PCR in stable and exacerbated COPD. Thorax 2012; 67: 1075-1080.

3 Singh S, Amin AV, Loke YK. Long-term use of inhale corticosteroids and the risk of pneumonia in chronic obstructive pulmonary disease. Arch Intern Med 2009; 169: 219-229.

$4 \mathrm{Kim}$ JH, Park JS, Kim KH, et al. Inhaled corticosteroid is associated with an incerased risk of TB in patients with COPD. Chest 2013; 143: 1018-1024.

5 Miravitlles M, Moragas A, Hernández S, et al. Is it possible to identify exacerbations of mild to moderate COPD that do not require antibiotic treatment? Chest 2013; 144: 1571-1577.

6 Miravitlles M, Kruesmann F, Haverstock D, et al. Sputum colour and bacteria in chronic bronchitis exacerbations: a pooled analysis. Eur Respir J 2012; 39: 1354-1360.

7 Bafadhel M, McKenna S, Terry S, et al. Acute exacerbations of chronic obstructive pulmonary disease. Identification of biologic clusters and their biomarkers. Am J Respir Crit Care Med 2011; 184: 662-671.

8 Donaldson GC, Seemungal TAR, Bhowmik A, et al. Relationship between exacerbation frequency and lung function decline in chronic obstructive pulmonary disease. Thorax 2002; 57: 847-852.

9 Wilkinson TMA, Patel IS, Wilks M, et al. Airway bacterial load and FEV1 decline in patients with chronic obstructive pulmonary disease. Am J Respir Crit Care Med 2003; 167: 1090-1095.

10 Miravitlles M, Ferrer M, Pont A, et al. Effect of exacerbations on quality of life in patients with chronic obstructive pulmonary disease: a 2 year follow up study. Thorax 2004; 59: 387-395.

11 Martínez-García MA, De la Rosa Carrillo D, Soler-Cataluña JJ, et al. Prognostic value of bronchiectasis in patients with moderate-to-severe chronic obstructive pulmonary disease. Am J Respir Crit Care Med 2013; 187: 823-831.

12 Renom F, Yáñez A, Garau M, et al. Prognosis of COPD patients requiring frequent hospitalization: Role of airway infection. Respir Med 2010; 104: 840-848.

13 Matkovic Z, Miravitlles M. Chronic bronchial infection in COPD. Is there an infective phenotype? Respir Med 2013; 107: 10-22.

14 George SN, Garcha DS, MacKay AJ, et al. Human rhinovirus infection during naturally-occurring COPD exacerbations. Eur Respir J 2014; 44: 87-96.

15 Monsó E, Ruiz J, Rosell A, et al. Bacterial infection in chronic obstructive pulmonary disease. A study of stable and exacerbated outpatients using the protected specimen brush. Am J Respir Crit Care Med 1995; 152: 1316-1320.

16 Hill AT, Campbell EJ, Hill SL, et al. Association between airway bacterial load and markers of airway inflammation in patients with stable chronic bronchitis. Am J Med 2000; 109: 288-295.

17 Miravitlles M. Exacerbations of chronic obstructive pulmonary disease: when are bacteria important? Eur Respir $J$ 2002; 20: Suppl., 9s-19s.

18 Mohan A, Chandra S, Agarwal D, et al. Prevalence of viral infection detected by PCR and RT-PCR in patients with acute exacerbation of COPD: A systematic review. Respirology 2010; 15: 536-542.

19 Seemungal T, Harper-Owen R, Bhowmik A, et al. Respiratory viruses, symptoms, and inflammatory markers in acute exacerbations and stable chronic obstructive pulmonary disease. Am J Respir Crit Care Med 2001; 164: 1618-1623.

20 Papi A, Bellettato CM, Braccioni F, et al. Infections and airway inflammation in chronic obstructive pulmonary disease severe exacerbations. Am J Respir Crit Care Med 2006; 173: 1114-1121.

21 Wilkinson TMA, Hurst JR, Perera WR, et al. Effect of interactions between lower airway bacterial and rhinoviral infection in exacerbations of COPD. Chest 2006; 129: 317-324.

22 Mallia P, Message SD, Gielen V, et al. Experimental rhinovirus infection as a human model of chronic obstructive pulmonary disease exacerbation. Am J Respir Crit Care Med 2011; 183: 734-742.

23 Oliver BGG, Lim S, Wark P, et al. Rhinovirus exposure impairs immune responses to bacterial products in human alveolar macrophages. Thorax 2008; 63: 519-525.

24 Molyneaux PL, Mallia P, Cox MJ, et al. Outgrowth of the bacterial airway microbiome after Rhinovirus exacerbation of chronic obstructive pulmonary disease. Am J Respir Crit Care Med 2013; 188: 1224-1231.

25 Sethi S, Evans N, Grant BJ, et al. New strains of bacteria and exacerbations of chronic obstructive pulmonary disease. N Engl J Med 2002; 347: 465-471.

26 Anzueto A, Sethi S, Martinez FJ. Exacerbations of chronic obstructive pulmonary disease. Proc Am Thorac Soc 2007; 4: 554-564.

27 Matkovic Z, Huerta A, Soler N, et al. Predictors of adverse outcome in patients hospitalised for exacerbation of COPD. Respiration 2012; 84: 17-26.

28 Wilkinson TMSA, Donaldson GC, Hurst JR, et al. Early therapy improves outcomes of exacerbations of chronic obstructive pulmonary disease. Am J Respir Crit Care Med 2004; 169: 1298-1303.

29 Hurst JR, Donaldson GC, Wilkinson TMA, et al. Epidemiological relationships between the common cold and exacerbation frequency in COPD. Eur Respir J 2005; 26: 846-852.

30 Miravitlles M, Soler-Cataluña JJ, Calle M, et al. Treatment of COPD by clinical phenotypes. Putting old evidence into clinical practice. Eur Respir J 2013; 41: 1252-1256. 